\title{
Construction of English Audiovisual Material Corpus for English Majors Based on Constructivism
}

\author{
Jinling Song ${ }^{1}$, Li Zhang ${ }^{2, *}$ \\ ${ }^{1}$ School of Foreign Languages, Tonghua Normal University, Tonghua, Jilin China \\ ${ }^{2}$ School of Physics, Tonghua Normal University, Tonghua, Jilin China \\ *dbcy9999@163.com
}

Keywords: selection of audiovisual materials, situated instruction, socio-cultural theory.

\begin{abstract}
With the development of multimedia adopted in teaching, audiovisual class emerges in recent years. The new teaching mode has stimulated the students' interest and soon made the course a compulsory subject. However, the absence of a scientific material corpus leads to the random selection of materials and makes the class reduced to an entertaining class. This is far from achieving the teaching goal. The theory of constructivism about learning elements will help to build a scientific corpus of audiovisual materials, and this will finally help achieve the teaching goal and bring about satisfactory teaching effect.
\end{abstract}

\section{Introduction}

With the internet resources becoming more and more abundant, English audiovisual class has become an impulsive subject in many universities. Aided with the multi-media measures, this course has presented its advantage with various video materials, changing the traditional teaching mode. The authentic audiovisual materials effectively improved students' oral English, which gains its recognition in College English teaching. However, the absence of corpus leads to the random and one-sided choice of visual materials. Without a scientific and reasonable choice of materials, teachers often choose some popular Hollywood movies, most often action movies, to satisfy the students' needs. Even though those movies brim over with fantastic plots and marvelous pictures, they would not effectively improve students' literary accomplishment. Thus, it is of crucial importance to construct a corpus of audiovisual materials based on the theory of constructivism.

\section{The Agreement between Constructivism and audiovisual class}

As a branch of cognitive psychology, Constructivism emerges in the 1960s. Based on Behaviorism, cognition and social and cultural theory, Swiss psychologist Piaget developed the theory, which broke the traditional teaching mode and the relationship between teachers and students, redefining "knowledge", "teaching" and "learning". The conception of study from the Constructivism perspective regards study as the students' activity of constructing their knowledge tower. With the help of others (teachers and friends), learners acquire their knowledge through some certain circumstance(social and cultural background). They make use of the learning materials and construct the knowledge system actively. Therefore, circumstance, cooperation, conversation and construction of meaning are classified as the four basic elements of learning environment. Constructivists emphasize the central role of students has changed from a passive receiver to an active processor. Students are expected to make hypothesis of the knowledge and check the answers by themselves. In contrast, teachers have changed from the previous role as a leader to the role as an assistant who help the students in their knowledge construction.

The English audiovisual class evolves from the traditional listening class, which inherited the characteristic of promoting students' listening ability. It provides the students with more vivid video materials, overcoming the drawback of students' easy distraction on traditional class. What's more important, the corpus of audiovisual materials would provide a better learning environment, create more opportunities for conversation, and help students construct their learning system more 
effectively. It can be concluded the appropriate choice of materials has a direct relation to the students' learning outcome. There is no doubt that taking the constructivist theory into consideration when selecting the audiovisual materials would ensure a better teaching effect and promise a greater advantage of this course.

\section{Selecting the materials based on constructivism}

\subsection{Selecting the classical documentaries based on socio-cultural theory}

The socio-cultural theory is the key study of the Russian psychologist and educationist Lev Vygotsky in the 20 century. He defines language as a cultural activity. By passing cultures, language fulfils the purpose of expressing ideas and communication.[1] Bruner argued that individuals take language as a medium, make choices when dealing with belief, viewpoint, attitude, and behavior by using their own cultural resources, building and adjusting self-recognition and meanwhile developing their own world vision.[2] Cultural difference and cultural deprivation are the two poles of recognition. Those who have stronger self-awareness are more competent in converting culture than those who haven't. This is because the former has more potential for modification, which helps them overcome the inborn weakness of their recognition function.[3] It can be seen that one can improve his ability of accepting cultural difference by getting in touch with different culture, by which one could get himself accustomed to the multi-cultural society.

From this perspective, the corpus of English major audiovisual course should include classical documentaries about English countries, such as those issued by BBC, Discovery Channel, National Geographic, presenting humanity, geography, history, nature, science, etc. Students may have a better understanding of the western perspective. While appreciating the western culture, they may enhance their perception of the medium of culture-language. Language is the medium of culture, while culture is the origin of language. They are two closely related parts. Only when the students understand the core of the target language can they achieve the construction of their knowledge. The documentaries which bear the culture element may help the students overcome their weakness of recognition ability, enable them to learn language with a higher efficiency and improve their ability of accepting cultural difference, which is an indispensable part for language learners. According to Vygotsky's socio-cultural theory, the process of learning is a process of crossing culture. It concerns the cross from cultural practices to cultural experience and to cultural development, and classical documentary is an effective medium for achieving this aim.

\subsection{Selecting the authentic news based on situated instruction theory}

The constructivist theory emphasizes the importance of situated instruction, advocating that language learning should take place in real situation.[4] It means that learning should be based on solving problems in reality. Those situations, which are closer to life may exert a sense of familiarity, are easier for the students to get into. The closer the situations to the real life, the better it will help the students in their language improvement. Meanwhile, the creation of situation and the events and characters in them will definitely influence students' view of life, values and view of society. Both the objectivity of documentaries and the drama of movies are inferior to the fact of news in creating an effective situation. It is because the news which is closely related to real life provides the correct values guidance is more suitable in promoting situated instruction.[5]

News materials, such as the American "The View", Chinese CCTV Dialogue, are English programs, which center on politics, economy, education, entertainment, health and other fields. Students of the new century should not only get to know the latest news and keep up with the fast development of the era, they should also develop the correct criteria for making judgment. The news program lacks in making legal or moral comment, but the interview program could fill the gap. When students view such video materials, they will accept the knowledge and store it into their knowledge structure according to the understanding of language situation. 


\subsection{Selecting the light comedy based on cooperation theory}

Students' different background and way of understanding lead to their different ability of recognition, and this presents the differences in language learning. Although students may have similar understanding of the content of one material, the range of using the material may vary from student to student.[6] For example, some students may not fully grasp the usage of some euphemism or sarcastic words due to their poor understanding ability. Constructivist advocates the cooperation among teachers and students, encouraging that the teacher acts as a guide. Only in this way could the understanding of language material be appropriate and accurate.[7] This will lead the students to enrich their understanding and help them grasp the knowledge more accurately.

Light comedies like Friends or The Big Bang Theory present the characteristics of simple language, close-to-life plot, and humorous style. They provide the students with abundant and attractive language materials, enabling the language learners to organize simple plays of imitation. In the process of re-presenting the play, students will have the opportunity to organize and edit, which requires the cooperation and communication among the students. This will contribute to the in-time correction of wrong understanding and ensure the correct master of language meaning.

\subsection{Selecting the classical movies based on conversation theory}

Friderick Klippel argues that if learners take part in the process actively, then the study would turn out to be more effective.[8] Constructivist emphasizes students not only need situations to learn, but also the interactions of three aspects in order to fulfill the construction. They are the interactions between students and materials, teachers and students, students and students. The traditional class lays too much stress on single transmit of message, neglecting the interaction part, which lead to the students' focusing on receiving the knowledge but failing to process it.[9] This leads to the inconsistency and loss of knowledge and makes the teaching unsatisfactory. The audiovisual class allocates more time for students to practice conversation, ensuring the important step of construction.[10] Thus the selection of video materials which can stimulate students to talk is of great importance.

Literature is always considered to be human's priceless treasure. In recent years, with the fast development of movie industry, more and more literary classics have been edited into movies. These movies could not only cultivate students' literature accomplishment but also provide a great amount of material for conversations. Although art is valued as superior to life, it still comes from life. Students may find it easy to get into the story and strike a chord with the characters. After the appreciation of the movie, they may exchange their attitudes and ideas about the characters, themes and ways of expressions. This will stimulate the students to make use of their gained knowledge, rebuilding the structure by adding new information and bringing the construction onto a new level.

With the construction of the material corpus, the audiovisual class would fulfil a learning process as shown in the following figure.
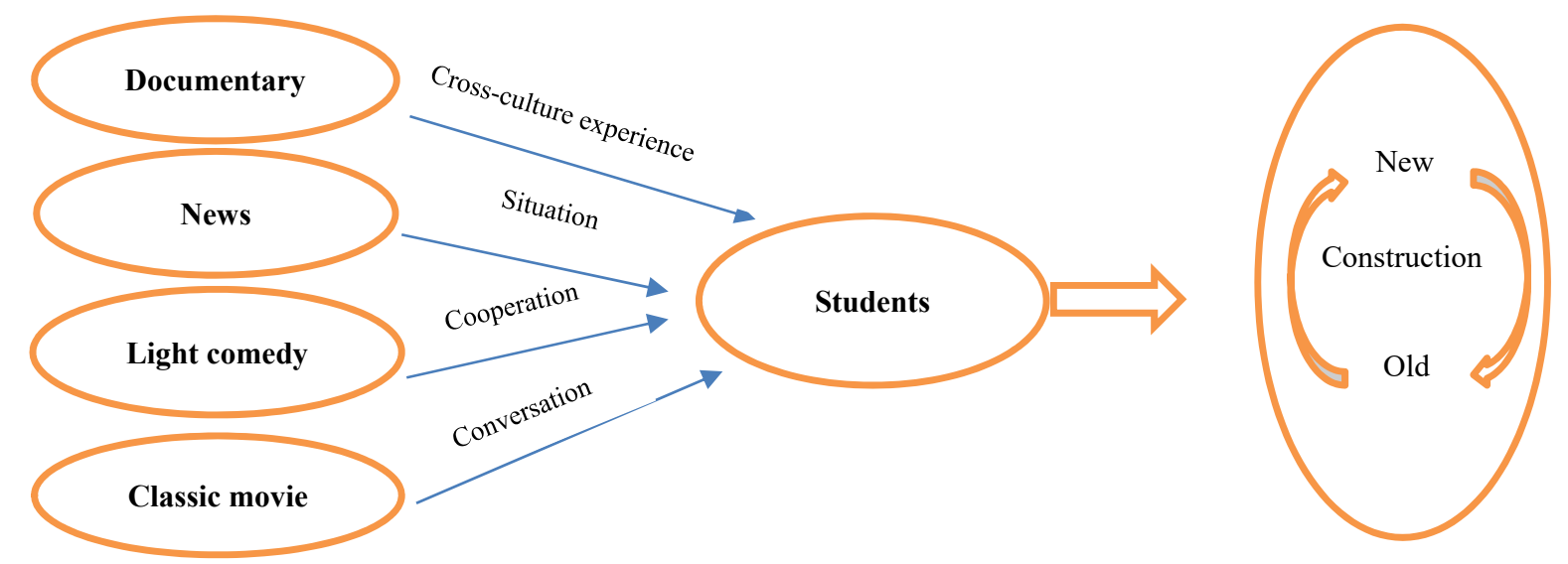

Fig. 1. The audiovisual class would fulfill a learning process 


\section{Conclusion}

The selection of materials for the audiovisual class plays an important role in deciding the success of teaching. Teachers should have a good knowledge of the characteristics of students' constructing knowledge system in order to choose the appropriate input materials and make sure the improvement of language learning. The qualified materials should be those which carry the literary ethos and cultural breath of English countries. They could not only help to elevate students in their literature accomplishment and cross culture ability, but also cultivate students' sharp insight of news. Good teaching materials is the good start of effective teaching. There is no doubt that the corpus based on constructivism advance the development of the audiovisual class.

\section{References}

[1] Lebow. David, Constructivist values for instructional systems design: Five principles toward a new mindset, Educational technology Research and Development, vol.16, pp. 106-108, 1993.

[2] J. Bruner, Acts of meaning, Cambridge. MA: Harvard University Press, vol. 2, pp. 68-70, 1990.

[3] R. Feuerstein, The theory of structural cognitive modifiability, Presseisen. Learning and thinking styles: Classroom interaction, vol.5, pp.68-70, 1990.

[4] Jiang-hua $\mathrm{Fu}$, The revolution and renovation of audiovisual teaching, Journal of Jiangxi Agriculture University, vol. 12, pp. 76-80, 2002.

[5] Lin-li Liu, The renovation of foreign language news in audiovisual teaching mode from the perspective of constructivism, The Media, vol. 3, pp. 56-58, 2012.

[6] Ming Ni, A study of Vygotsky's teaching idea and essence, Journal of Xi'an Art and Science College, vol. 3, pp. 83-86, 2010.

[7] Li Qiu, On the development of students' communication ability in audiovisual class, Journal of Anhui Agriculture College, vol. 1, pp. 26-28, 2005.

[8] Tao Wang, Vygotsky's constructivism, Social Science of Guang Xi, vol. 2, pp. 66-69, 2006.

[9] Bi-fang Yu, Studying the teaching mode of audiovisual class from the constructivism perspective, Journal of Fu Jian Normal University, vol. 6, pp 76-78, 2009.

[10]Kun-mao Zhong, The English audiovisual class and English documentary, Journal of Longyan College, vol.2, pp. 36-39, 2007. 